\title{
The Paris Cardiovascular Risk Factor Prevention Trial Effects of two years of intervention in a population of young men
}

\author{
F. CAMBIEN, ${ }^{1}$ J. L. RICHARD,,$^{1}$ P. DUCIMETIERE,,$^{2}$ J. M. WARNET, ${ }^{3}$ AND \\ J. KAHN ${ }^{1}$ \\ From 'l'Equipe de Recherche Cardiologie, INSERM, Paris, 2l'Unité de Recherche Statistique et \\ Epidémiologique, INSERM, Villejuif, et 'le Laboratoire de Recherche sur les Maladies Cardiovasculaires de la \\ Direction Departementale des Affaires Sanitaires et Sociales, Paris
}

SUmmary The Paris Cardiovascular Risk Factor Prevention Trial was designed to determine whether individualised intervention could induce a reduction in the coronary risk factor levels in young men. Three thousand three hundred and thirty-six men aged 25 to 35, working in the 160 sections of a large Parisian administration, were examined. The sections were randomly allocated to a control and an intervention group. Advice concerning diet, cigarette smoking, and physical activity was provided repeatedly to the subjects in the intervention group. Two years after the first intervention, the first 1292 subjects who entered the study, whether from the intervention or the control group, were recalled; $86 \%$ of the intervention group and $84 \%$ of the control group responded. The changes in weight, blood pressure, and cigarette smoking in the intervention group, corrected for changes in the control group, were respectively $-0.4 \mathrm{~kg}(\mathrm{p}=0.06),-1.4 \mathrm{~mm}$ $\mathrm{Hg}(\mathrm{p}<0.05)$, and -1.2 cigarettes $(\mathrm{p}<0.01)$. There was no difference between the two groups in serum cholesterol change. Most of these results concerning young men are in agreement with recently reported results of community intervention programmes in middle-aged men.

The association between the incidence of coronary heart disease (CHD) and the levels of blood pressure, plasma cholesterol, and cigarette consumption is now well-established. As the levels of these risk factors can be modified by some intervention, many prevention trials have been organised to test the hypothesis that intervention can also reduce the recurrence or the incidence of CHD.

Multifactorial prevention trials constitute a pragmatic approach and if their efficiency can be proved their methods of intervention could be extended to larger populations. At the present time, many multifactorial primary prevention trials on middle-aged men free of CHD at entry are under way. ${ }^{1 \rightarrow}$ The first question that such trials must answer is: "Can this kind of intervention reduce the level of coronary risk factors or prevent their increase?'

The Paris trial was organised to test the short- and middle-term effects of an intervention programme on modifications of the levels of risk factors in men aged 25 to 35 , before the occurrence of extended coronary lesions. Preventive measures in young adults, if observed, are expected to have more effect on the atherosclerotic process than in middle-aged subjects, but it is also probable that young subjects are less well-motivated towards prevention. In young men, risk factors increase rapidly, partly for intricate sociological reasons, and the aim of intervention is mainly to prevent such an increase rather than to reduce risk factors.

To increase the efficiency of the trial, it was decided to intervene more frequently in a group of subjects with elevated risk factors (cigarette smoking, plasma cholesterol, blood pressure). In young men, however, elevation of these risk factors is relatively rare, and consequently men who were substantially overweight, even without other abnormalities, were also included in the high-risk group. The organisation of the trial is shown in the Figure.

\section{Material and methods}

STUDY POPULATION AND SAMPLE

The population of the study was composed of 32000 civil servants from a Parisian administration. Each individual in this population is submitted to a cardiovascular screening every five years. Included in the prevention trial were all the men aged 25 to 35 who came to the screening centre between February 


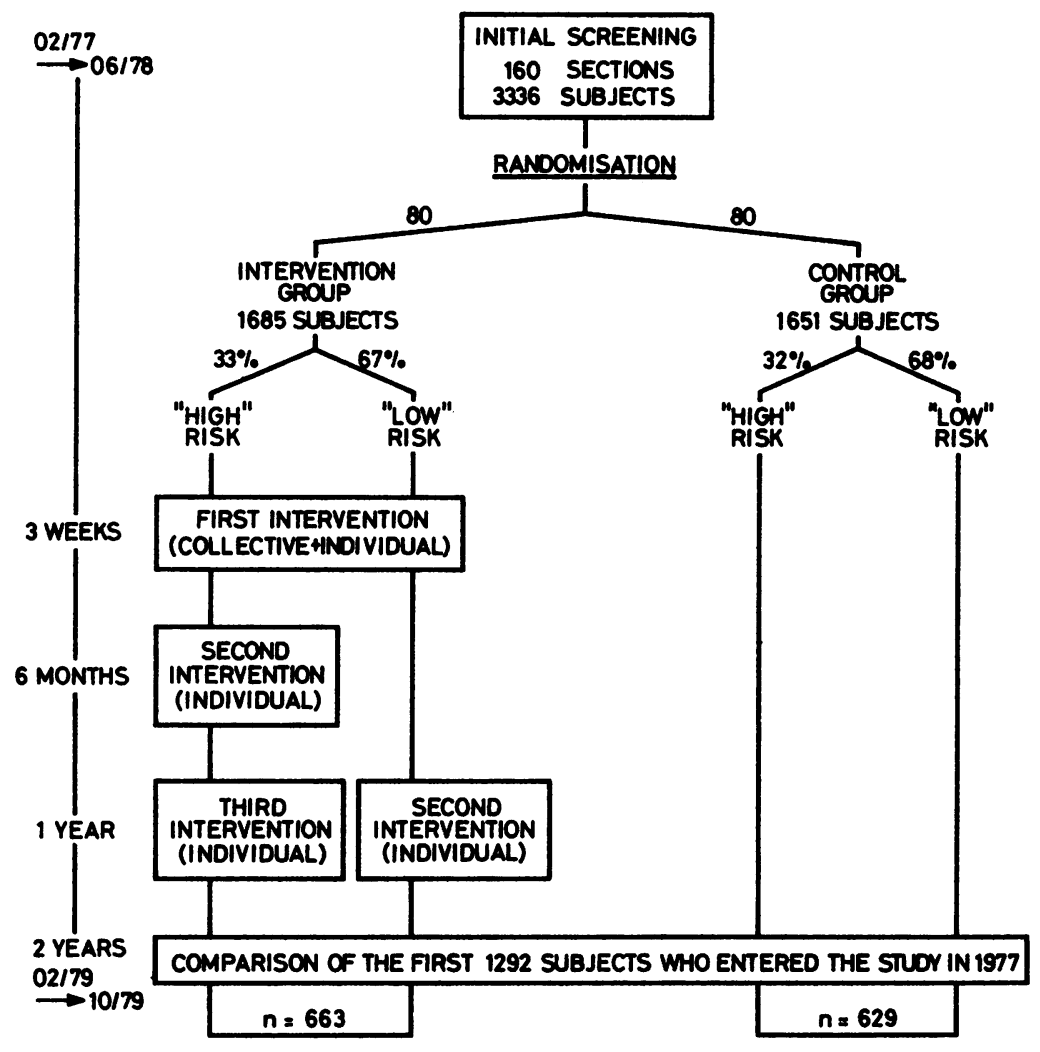

Figure Organisation of the trial.

1977 and June 1978, that is, 3336 subjects belonging to 160 sections.

It is important to emphasise that the examination is not compulsory. The subjects are sent by their departments but are not convoked by the medical offices, so it is impossible to give precise data on the participation rate, but this may be considered very good in so far as the examination entitles the subject to a day off.

\section{THE INITIAL SCREENING}

Three thousand three hundred and thirty-six men aged 25 to 35 entered the study. The baseline examination included a measurement of height and weight, a clinical examination, a 12-lead ECG recording, and a screening for risk factors. Blood pressure was measured at rest with a mercury sphygmomanometer, plasma cholesterol was determined by an automatic method with hoang reagent ${ }^{7}$ from a venous sample taken at the beginning of the morning, and a detailed history of cigarette consumption was obtained by questionnaire.
RAN DOMISATION

Sections were randomly assigned to the intervention group (80 sections, 1685 subjects) and the control group (80 sections, 1651 subjects).

\section{RISK SCORE}

For each subject, a risk score ( $R$ ) was computed using a risk function derived from the results of the Paris Prospective Study":

$R=1.0 \times$ plasma cholesterol $(\mathrm{mg} / 100 \mathrm{ml})+1.5 \times$ systolic blood pressure $(\mathrm{mm} \mathrm{Hg})+2.6 \times$ no. of cigarettes a day.

\section{HIGH-RISK SUBJECTS}

Thirteen per cent of the subjects with $\mathbf{R}$ greater than 480 and $20 \%$ of the remaining subjects, with weight indices* greater than 26.6 were included in the high-risk group, which finally consisted of $32 \%$ of the whole sample.

\section{FIRST INTERVENTION}

All the subjects in the intervention group were recalled three weeks after the initial screening, to 
complete a self-administered questionnaire on diet, to receive some information on coronary risk factors, and to be given preventive advice. The intervention included audiovisual and printed information provided at the clinic and a personal interview with a specially trained doctor who had in his possession the results of the initial screening and the dietary questionnaire.

The first purpose of the dietary questionnaire was to give the doctor a pattern of dietary habits which might help him to formulate his advice. It included 23 questions and each question offered only three possibilities of answer.

\section{EXAMPLE}

Do you eat meat once a day once a day

Do you drink milk yes skimmed

milk never or rarely

Do you eat fish more than once a week

$$
\text { once a }
$$

a week

When an answer was in the right hand column, the doctor had to give systematically specific advice. The left hand column was supposed to indicate the ideal consumption.

As a rule, advice was given with the idea that in young adults, except in very special cases, risk factors (cigarette smaking, weight, plasma cholesterol, blood pressure) should be kept at the lowest possible level. Complete cessation of smoking was recommended, regardless of the number of cigarettes smoked. Dietary advice was given according to weight, plasma cholesterol level, blood pressure, and the information given in answers to the self-administered questionnaire. Reductions in the consumption of saturated fats, alcoholic beverages, refined sugars, and salt, and increases in the consumption of polyunsaturated fats, vegetables, and fruit were recommended, depending on the case.

FURTHER EXAMINATIONS AND INTERVENTIONS High-risk subjects were recalled at six and 12 months, low-risk subjects at 12 months. At each visit, a blood sample was taken, weight and blood pressure were measured, and a doctor examined the subjects. Depending on the weight and blood pressure changes, and on the subjects' answers to a series of standardised questions about their adherence to the recommendations given during the previous intervention, the doctor repeated or modified these recommendations, which could also be modified by letter after plasma cholesterol values were known.

\section{COMPARISON EXAMINATION AFTER TWO YEARS} OF INTERVENTION

For the purpose of comparison after two years, it was decided to recall the first 1292 subjects who entered the study, whether from the intervention group or the control group. The protocol of this examination was the same as that of the initial screening, plus a self-administered questionnaire on dietary habits and a measurement of blood carbon monoxide.

\section{Results}

\section{RESPONSE RATES}

Between the first screening and the last examination two years later, the high-risk subjects of the intervention group were recalled three times and the low-risk subjects twice. Attendance rates ranged from $95 \%$ for the first re-examination to $80 \%$ for the last two examinations in the high-risk subjects of the intervention group. Participation in the comparison examination was $86 \%$ in the intervention group and $84 \%$ in the control group. The percentages were $80 \%$ and $84 \%$ respectively for high-risk subjects (Table 1 ).

COMPARABILITY AT ENTRY, ACCORDING TO PARTICIPATION AT THE LAST EXAMINATION

The $14 \%$ of subjects lost to follow-up in the intervention group smoked on average 4.4 cigarettes a day more than the attenders $(p<0.01)$ (Table 2). On the other hand, this difference was only 0.4 cigarettes a day in the control group. Thus, there was clearly a selection due to intervention. The mean

-A blood sample was obtained by venous puncture on EDTA. Carbon monoxide was measured by the infra-red non-dispersive method of Boudene." The results are expressed in millilitres of carbon monoxide per $100 \mathrm{ml}$ of blood $\times 100$.

\begin{tabular}{|c|c|c|c|c|c|c|}
\hline & \multicolumn{3}{|c|}{ INTERVENTION GROUP } & \multicolumn{3}{|c|}{ CONTROL GROUP } \\
\hline & $\begin{array}{l}\text { Low-risk } \\
(n=442)\end{array}$ & $\begin{array}{l}\text { High-risk } \\
(n=221)\end{array}$ & $\begin{array}{l}A l l \\
(n=663\end{array}$ & $\begin{array}{l}\text { Low-risk } \\
(n=426)\end{array}$ & $\begin{array}{l}\text { High-risk } \\
(n=203)\end{array}$ & $\begin{array}{l}A \| \\
(n=629)\end{array}$ \\
\hline $\begin{array}{l}\text { First intervention } \\
\text { Six months intervention } \\
\text { One year intervention } \\
\text { Comparison examination }\end{array}$ & $\begin{array}{l}95 \cdot 2 \% \\
\overline{91} \cdot 0 \% \\
88 \cdot 5 \%\end{array}$ & $\begin{array}{l}96.4 \% \\
90.5 \% \\
79.6 \% \\
80.1 \%\end{array}$ & $\begin{array}{l}95 \cdot 6 \% \\
-77 \cdot 2 \% \\
85 \cdot 7 \%\end{array}$ & $\begin{array}{l}- \\
\overline{-} \\
84 \cdot 0 \%\end{array}$ & $\begin{array}{l}\overline{-} \\
\overline{84 \cdot 2 \%}\end{array}$ & $\begin{array}{l}- \\
\overline{-} \\
84 \cdot 1 \%\end{array}$ \\
\hline
\end{tabular}


Table 2 Comparison of risk factors at entry for subjects recalled after two years in relation to presence or absence at last examination

\begin{tabular}{|c|c|c|c|c|c|c|}
\hline \multirow[b]{2}{*}{ Seen at recall } & \multicolumn{3}{|c|}{ CONTROL GROUP } & \multicolumn{3}{|c|}{ INTERVENTION GROUP } \\
\hline & Yes & No & All & Yes & No & $A l l$ \\
\hline $\begin{array}{l}\text { Number } \\
\text { Mean age } \pm \text { SD } \\
\text { Mean weight } \pm \text { SD (kg) } \\
\text { Mean systolic blood pressure } \pm \text { SD } \\
\quad(\mathrm{mm} \mathrm{Hg})\end{array}$ & $\begin{array}{r}529(84 \%) \\
28 \cdot 8 \pm 3 \cdot 0 \\
74 \cdot 0 \pm 10 \cdot 0 \\
126 \cdot 3 \pm 11 \cdot 0\end{array}$ & $\begin{array}{r}100(16 \%) \\
29 \cdot 2 \pm 3 \cdot 0 \\
73.8 \pm 9.6 \\
125 \cdot 8 \pm 14.4\end{array}$ & $\begin{array}{l}629 \\
28.9 \pm 3.0 \\
74.0 \pm 9.9 \\
126.2 \pm 11.6\end{array}$ & $\begin{array}{rr}568 \quad(86 \%) \\
28 \cdot 6 \pm 3 \cdot 1 \\
74 \cdot 7 \pm 9.9 \\
126.5 \pm 10.9\end{array}$ & $\begin{array}{r}95(14 \%) \\
28 \cdot 5 \pm 3 \cdot 1 \\
75 \cdot 0 \pm 11 \cdot 1 \\
127 \cdot 2 \pm 10 \cdot 9\end{array}$ & $\begin{array}{r}663 \\
28 \cdot 6 \pm 3 \cdot 1 \\
74 \cdot 7 \pm 10 \cdot 1 \\
126 \cdot 6 \pm 10 \cdot 9\end{array}$ \\
\hline $\begin{array}{l}\text { Mean plasma cholesterol } \pm \text { SD } \\
(\mathrm{mg} / 100 \mathrm{ml})\end{array}$ & $205 \cdot 2 \pm 41 \cdot 4$ & $207 \cdot 1 \pm 44 \cdot 0$ & $205 \cdot 5 \pm 41 \cdot 8$ & $208 \cdot 1 \pm 42 \cdot 3$ & $206 \cdot 3 \pm 45 \cdot 7$ & $207 \cdot 8 \pm 42 \cdot 8$ \\
\hline Mean cigarettes/day $\pm S D$ & $9 \cdot 9 \pm 12 \cdot 1^{a}$ & $10 \cdot 4 \pm 11 \cdot 3$ & $10.0 \pm 12.0$ & $8 \cdot 3 \pm 10 \cdot 4^{b}$ & $12 \cdot 7 \pm 13 \cdot 3^{c}$ & $8.9 \pm 11.0$ \\
\hline
\end{tabular}

Table 3 Mean changes in risk factors in control and intervention groups between first and last examinations

\begin{tabular}{|c|c|c|c|c|c|c|}
\hline & \multicolumn{2}{|c|}{ ALL SUBJECTS } & \multicolumn{2}{|l|}{ LOW-RISK } & \multicolumn{2}{|l|}{ HIGH-RISK } \\
\hline & Control & Intervention & Control & Intervention & Control & Intervention \\
\hline $\begin{array}{l}\text { No. of subjects } \\
\text { Weight }(\mathrm{kg}) \\
\text { Systolic blood pressure }(\mathrm{mm} \mathrm{Hg}) \\
\text { Plasma cholesterol }(\mathrm{mg} / 100 \mathrm{ml}) \\
\text { Cigarettes/day }\end{array}$ & $\begin{array}{l}529 \\
+1 \cdot 2 \pm 3 \cdot 5 \\
+1 \cdot 6 \pm 11 \cdot 7 \\
+3 \cdot 0 \pm 31 \cdot 0 \\
-1 \cdot 0 \pm 8 \cdot 3\end{array}$ & $\begin{array}{l}568 \\
+0 \cdot 8 \pm 3 \cdot 4 \\
+0 \cdot 2 \pm 12 \cdot 1^{*} \\
+2 \cdot 1 \pm 29 \cdot 4 \\
-2 \cdot 2 \pm 7 \cdot 3^{* *}\end{array}$ & $\begin{aligned} & 358 \\
&+1.4 \pm \\
&+1.6 \pm 11.3 \\
&+7.0 \pm 25.9 \\
&+0.1 \pm 6.6\end{aligned}$ & $\begin{array}{l}391 \\
+1 \cdot 2 \pm 2 \cdot 9 \\
+1 \cdot 0 \pm 11 \cdot 9 \\
+5 \cdot 8 \pm 27 \cdot 6 \\
-1 \cdot 2 \pm 6 \cdot 3 * *\end{array}$ & $\begin{array}{l}171 \\
+0 \cdot 6 \pm 4 \cdot 1 \\
+1 \cdot 7 \pm 12 \cdot 5 \\
-5 \cdot 2 \pm 38 \cdot 4 \\
-3 \cdot 1 \pm 10 \cdot 7\end{array}$ & $\begin{array}{l}177 \\
-0 \cdot 2 \pm 4 \cdot 2 \\
-1 \cdot 6 \pm 12 \cdot 3 * \\
-6 \cdot 1 \pm 31 \cdot 5 \\
-4 \cdot 4 \pm 8 \cdot 9\end{array}$ \\
\hline
\end{tabular}

Comparison of control and intervention groups (Student's $t$ test)

$p<0.05$

$* p<0.01$.

cigarette consumption at entry, irrespective of attendance at the last examination, was 8.9 a day in the intervention group and 10.0 in the control group. This non-significant difference, added to the selection mentioned above, explains why the subjects in the intervention group who were present at the last examination had a significantly lower initial mean cigarette consumption than the subjects in the control group : $8 \cdot 3$ and $9 \cdot 9$ cigarettes respectively $(p<0.05)$. The other risk factors did not differ at entry, relative to the presence or absence of the subjects at the last examination.

\section{MODIFICATIONS OF THE RISK FACTORS DURING} THE TRIAL

The mean variations of the risk factors between the first and the last examinations are given in Table 3. The change in weight in the intervention group, corrected for the change in weight in the control group (that is, the difference of change between the two groups) was $-0.4 \mathrm{~kg}(\mathrm{p}=0.06)$. The corrected change in mean systolic blood pressure in the intervention group was $-1.4 \mathrm{~mm} \mathrm{Hg}(\mathrm{p}<0.05)$. Both groups reduced their cigarette consumption; the corrected mean reduction in the intervention group was 1.2 cigarettes a day $(p<0.01)$. In the intervention group, $23 \cdot 1 \%$ of the initial smokers stopped cigarette smoking (compared with $14.3 \%$ in the control group), and $26.7 \%$ reduced their cigarette consumption (compared with $18.8 \%$ in the control group). Neither of these differences is statistically significant. The increase in plasma cholesterol was approximately the same in the two groups $(2 \mathrm{mg}$ per $100 \mathrm{ml}$ ).

High-risk subjects After corrections for change in the control group, the mean reductions of weight, systolic blood pressure, and cigarette consumption in the intervention group were $-0.8 \mathrm{~kg},-3.3 \mathrm{~mm} \mathrm{Hg}$, and $-1 \cdot 3$ cigarettes a day respectively. The substantial reduction of cigarette consumption in the control group must be noted.

Low-risk subjects After corrections for changes in the control group, the mean reduction of weight, systolic blood pressure and cigarette consumption in the intervention group were $-0.2 \mathrm{~kg},-0.6 \mathrm{~mm} \mathrm{Hg}$, and $-1 \cdot 3$ cigarettes a day respectively.

On the whole, there seemed to be a weak favourable effect of intervention on weight, blood pressure, and cigarette consumption, but no effect at all on plasma cholesterol.

MODIFICATIONS OF WEIGHT WHEN MODIFICATIONS OF CIGARETTE CONSUMPTION ARE TAKEN INTO ACCOUNT

The weight gain associated with stopping cigarette smoking is well known, so it seemed worthwhile to verify if this gain was found in the present data for subjects who stopped or reduced their cigarette consumption and to see if it substantially altered the effects of intervention on weight.

Three groups were formed: (1) subjects who stopped smoking during the study; (2) subjects who 
reduced their cigarette consumption by more than three cigarettes a day; and (3) other smokers and non-smokers. In these three groups, weight changes were compared between the control and the intervention group (Table 4). In the group of subjects who stopped smoking, weight gain was marked, especially in the control group ( $3.4 \mathrm{~kg}$ compared with $2.2 \mathrm{~kg}$ in the intervention group). Subjects who reduced their cigarette consumption did not experience a similar weight gain despite an alleged reduction of 10.2 cigarettes a day in both groups. Consequently, the expected effect of reduction of cigarette consumption on weight was evident only in those who stopped smoking. In the third group, the mean change in weight in the intervention group, corrected for change in the control group, was $-0.3 \mathrm{~kg}$. When this is compared with the corrected change observed in the whole population $(-0.4 \mathrm{~kg})$, it shows that the rather weak effect of intervention on controlling weight is not a consequence of the greater reduction of cigarette consumption in the intervention group.

BLOOD CARBON MONOXIDE LEVELS IN SUBJECTS WHO STOPPED OR REDUCED THEIR CIGARETTE CONSUMPTION AND IN OTHER SMOKERS AND NON-SMOKERS

Blood carbon monoxide was measured at the last examination in the intervention and control groups as an objective check on the cigarette consumption reported by questionnaire (Table 5). For smokers, the correlations between blood carbon monoxide and the reported cigarette consumption were 0.52 and 0.54 in the control and the intervention group respectively. In the subgroup of subjects who stopped smoking, the mean levels of blood carbon monoxide in the intervention and in the control group were comparable, and seemed to confirm the responses of the subjects or at least to exclude a bias due to differential responses in the control and the intervention groups. It must be noted, however, that in both groups the mean levels of blood carbon monoxide were significantly higher in those who stopped smoking than in non-smokers. For those who reduced their cigarette consumption, the final alleged consumption of the intervention group was lower than that of the control group, in spite of a higher mean blood carbon monoxide level, which suggests that the consumption is somewhat understated in the intervention group; but these differences are not statistically significant.

\section{Discussion}

Recently, preliminary results of three large-scale prevention trials ${ }^{510} 11$ and the final results of the North Karelia Project ${ }^{12}$ have been published. These trials have been planned to test the long-term effects of preventive measures on the incidence of coronary heart disease in middle-aged subjects. The reported results, in so far as they concern the effects of intervention on the short- and middle-term modifications of risk factor levels, can be compared to those of the present study, in spite of differences in the preventive approach and the age structure of the populations studied.

Weight In the Paris trial, the difference in the mean weight increase between the control and the

Table 4 Weight changes in control and intervention groups in relation to changes in cigarette consumption

\begin{tabular}{|c|c|c|c|c|c|c|}
\hline & \multicolumn{2}{|c|}{ STOPPED CIGARETTE SMOKING } & \multicolumn{2}{|c|}{ DECREASED CIGARETTE SMOKING } & \multicolumn{2}{|c|}{ NOCHANGE*OR INCREASE } \\
\hline & Control & Intervention & Control & Intervention & Control & Intervention \\
\hline $\begin{array}{l}\text { No. of subjects } \\
\text { Change in consumption of } \\
\text { cigarettes/day } \\
\text { Change in weight (kg) }\end{array}$ & $\begin{array}{l}41 \\
-15 \cdot 8 \\
+3 \cdot 4^{* *}\end{array}$ & $\begin{array}{l}-13 \cdot 5 \\
+2 \cdot 2^{* \ldots *}\end{array}$ & $\begin{array}{r}-10.2 \\
+0.7\end{array}$ & $\begin{array}{r}-10.2 \\
+0.2\end{array}$ & $\begin{array}{l}434 \\
+1.6 \\
+1.0\end{array}$ & $\begin{array}{l}428 \\
+0.9 \\
+0.7\end{array}$ \\
\hline
\end{tabular}

Includes non-smokers.

"p $<0.01$ when compared to no change or increase (control).

$* *$ "p $<0.01$ when compared to no change or increase (intervention).

Table 5 Comparison of cigarette consumption and blood carbon monoxide in control and intervention groups at end of study

\begin{tabular}{|c|c|c|c|c|c|c|c|c|}
\hline & \multicolumn{2}{|c|}{$\begin{array}{l}\text { STOPPED CIGARETTE } \\
\text { SMOKING }\end{array}$} & \multicolumn{2}{|c|}{$\begin{array}{l}\text { DECREASED CIGARETTE } \\
\text { SMOKING }\end{array}$} & \multicolumn{2}{|c|}{ OTHER SMOKERS } & \multicolumn{2}{|c|}{ NON SMOKERS } \\
\hline & Control & Intervention & Control & Intervention & Control & Intervention & Control & Intervention \\
\hline $\begin{array}{l}\text { No. of subjects } \\
\text { Final cigarette }\end{array}$ & 41 & 65 & 54 & 75 & 211 & 164 & 223 & 264 \\
\hline consumption/day & 0.0 & 0.0 & $\begin{array}{r}13.4 \pm 6.7 \\
p\end{array}$ & $\begin{array}{l}11 \cdot 1 \pm 5.7 \\
0.05\end{array}$ & $\begin{array}{r}19 \cdot 1 \pm 10 \cdot 9 \\
p\end{array}$ & $\begin{array}{l}16 \cdot 0 \pm 9.0 \\
0.01\end{array}$ & 0.0 & 0.0 \\
\hline $\begin{array}{l}\text { Final carbon monoxide } \\
(\mathrm{ml} / 100 \mathrm{ml} \text { of blood } \times 100)\end{array}$ & $51 \pm 34$ & $53 \pm 36$ & $114 \pm 65$ & $122 \pm 72$ & $123 \pm 80$ & $120 \pm 79$ & $38 \pm 18$ & $39 \pm 19$ \\
\hline
\end{tabular}


intervention groups is marked only for high-risk subjects $(-1 \cdot 0 \%)$. In the British trial, ${ }^{11}$ weight increased significantly less in the intervention group after two years $(-1 \cdot 2 \%)$, but this favourable effect was not sustained after five years. In the Three Community Studys there were no differences in weight increase after two years between the intervention and the control towns. The Finnish ${ }^{12}$ and the Belgian ${ }^{10}$ investigators did not give any results for weight.

Blood pressure The change in systolic blood pressure in the intervention group of the Paris trial, after correction for change in the control group, was statistically significant, with an average reduction of $2.5 \%$ for high-risk subjects. A favourable effect of intervention on systolic blood pressure was observed in all the studies reported and was generally slightly greater than in the Paris trial (between $-2.5 \%$ and $-5.0 \%$ in the random samples).

Plasma cholesterol There was no difference in plasma cholesterol change in the Paris trial between the intervention and the control groups. In the Three Community Study, the Belgian trial, and the North Karelia Project, a significant favourable effect of intervention was observed: the net reduction of plasma cholesterol was between two and four per cent. The British trial experienced a significant unfavourable effect of intervention at two years, the opposite was observed at four years, and at six years there was no effect at all.

Cigarette smoking In the Paris trial, both groups reduced cigarette consumption, and this reduction was significantly greater in the intervention group $(-12 \%$ after correction for change in the control group). In the Three Community Study, the mean reduction was greater in the town where face-to-face counselling was provided for the high-risk subjects, although the participation rate in that town was the lowest. In the British and the Belgian trials, after correction for change in the control groups, the mean alleged reduction of cigarette consumption in the intervention group was $-12 \%$ after two years. In the Finnish trial, this percentage was $-10 \%$ after five years.

In the Paris trial, the smaller weight gain associated with stopping smoking in the intervention group, though not significant, is in agreement with the findings of a previous study, ${ }^{13}$ which suggested that nutritional advice could have an important effect on preventing the weight gain associated with stopping cigarette smoking. The absence of weight gain in subjects who reduced their cigarette consumption is worth noting.

Among smokers, the correlations between blood carbon monoxide levels and reported cigarette consumption are the same in both groups of the Paris trial and are similar to, or stronger than, those reported in other studies for carboxyhaemoglobin, expired air carbon monoxide, and serum thiocyanate. ${ }^{14} 15$ The number of subjects compared is insufficient to draw definite conclusions, but the results suggest a possible overreporting of cigarette consumption reduction in the intervention group.

In comparing results of intervention trials, the following problems need special emphasis.

The choice of the experimental units has been discussed recently by Farquhar and by Sherwin, ${ }^{1617}$ who have listed the pros and cons of randomisation with the community as the sampling unit. In the Paris trial, randomisation was performed on groups, mainly to avoid ethical problems and contamination which would certainly have arisen if subjects in the same section had been indifferently assigned to the control or the intervention group. Nevertheless, this trial cannot be considered a community intervention like the other studies discussed previously, because information and advice were almost exclusively given to individuals, and there was no intervention at the level of the sections. Thus, the effect of the 'enhanced opportunities for information exchange', which is specific to community-based intervention, cannot be expected in the Paris trial. In the studies already reported, comparisons have been made on subjects, in spite of randomisation by groups. This procedure is open to criticism. ${ }^{18}$

In the intervention group of the Paris trial, subjects lost to follow-up smoked more at entry than those who attended the last examination (Table 3 ) but this was not true in the control group; it is probable that some heavy smokers were deterred by the intervention advice. This selection implies that the final comparison was not carried out on strictly comparable groups. This problem is probably not specific to the Paris trial : unfortunately, the other studies quoted in the present discussion did not give the initial risk factor levels of the subjects lost to follow-up.

In most preventive trials, the effects of a specific intervention (that is, a piece of advice) are confounded by many uncontrolled effects which are the consequences of the screening process. Among these uncontrolled effects, one can mention the so-called pressor effect, ${ }^{10}$ due to repeated measurements of blood pressure in the intervention group, which may affect the difference in blood pressure between the two groups, or the transitory weight reduction of subjects in the intervention group who follow the nutritional advice a few days before the examination. On the other hand, the consequences of the initial screening on the behaviour of the subjects in the control group cannot be evaluated, and it may induce an underestimation 
of the differences due to intervention. To disentangle the specific and unspecific effects of the kind described above, specially designed studies are necessary in which the random samples of the control and intervention groups examined at the beginning, during, and at the end of the study are different.

\section{Conclusion}

The preliminary results of the multifactorial trials already reported seem to confirm one another to support a favourable effect of intervention on the risk factor levels which, if sustained, could have a significant beneficial effect on CHD incidence. The Paris trial even suggests that this prevention could take place in early adult life. However, as has been pointed out in the preceding discussion, these studies suffer methodological pitfalls. Studies in which randomisation has been performed on subjects are under way ${ }^{123}$ and will probably provide less disputable information, though community-based intervention might be more efficient in modifying the behaviour of the subjects.

Reprints from Dr. F. Cambien, Equipe de Recherche Cardiologie, INSERM, 15 rue de l'Ecole de Médecine, 75006 PARIS.

The authors are in the Groupe d'Etude sur l'Epidémiologie de l'Athérosclérose, supported by grants from the French Ministry of Health.

\section{References}

${ }^{1}$ Wilhelmsen L, Tibblin G, Werkö L. A primary preventive study in Gothenburg, Sweden. Prev Med 1972; 1: 153-60.

${ }^{2}$ Leren P, Askevold EM, Foss OP, et al. The Oslo Study-cardiovascular disease in middle-aged and young Oslo men. Acta Med Scand 1975; suppl 588.

${ }^{3}$ The Multiple Risk Factor Intervention Trial (MRFT) : a national study of primary prevention of coronary heart disease. JAMA 1979; 235 : 825-7.
4Puska P, Koskela K, Pakarinen H, Puumalainen P, Soininen V, Tuomilchto J. The North Karelia Project : a programme for community control of cardiovascular diseases. Scand J Soc Med 1976; 4: 57-62.

- Farquhar JW, Wood PD, Breitrose H, et al. Community education for cardiovascular health. Lancet 1977; i: 1192-5.

- World Health Organisation European Collaborative Group. An international controlled trial in the multifactorial prevention of coronary heart disease. Int $J$ Epidemiol 1974; 3: 219-24.

${ }^{7}$ Etienne G, Papin JP, Renault H. Une méthode simple de dosage du cholestérol total par voie automatique. Ann Biol Clin (Paris) 1963; 21: 851-9.

- Richard JL, Ducimetière P, Bonnaud G, et al. Incidence et évaluation du risque de maladie coronarienne : L'étude prospective parisienne. Arch Mal Coeur 1977; 70: $531-40$.

- Boudene C, Godin J, Roussel A. Méthode de dosage de l'oxyde de carbone dans le sang sans extraction séparée préalable, par absorption sélective dans l'infrarouge. Arch Mal Prof 1973; 34: 449-53.

${ }^{10}$ Kornitzer M, De Backer G, Dramaix M, Thilly C. The Belgian heart disease prevention project. Modification of the coronary risk profile in an industrial population. Circulation 1980; 61: 18-25.

${ }^{1}$ Rose G, Heller RF, Pedoe HT, Christie DGS. Heart disease prevention project : a randomised controlled trial in industry. $\mathrm{Br}$ Med $J$ 1980; 280: 747-51.

${ }^{12}$ Puska P, Tuomilehto J, Salonen J, et al. Changes in coronary risk factors during comprehensive five-year community programme to control cardiovascular diseases (North Karelia project). Br Med J 1979; ii: 1173-8.

${ }^{12}$ Ducimetière $\mathrm{P}$, Kritsikis $\mathrm{S}$, Richard JL, Pequignot $\mathrm{G}$. Variation de poids des fumeurs d'âge moyen après modifications de leur consommation de tabac. $R e v$ Epidemiol Santé Publique 1978; 26: 195-8.

14 Vogt TM, Selvin S, Hulley SB. Comparison of biochemical and questionnaire estimates of tobacco exposure. Prev Med 1979; 8: 23-33.

${ }^{15}$ Cohen JD, Bartsch GE. A comparison between carboxyhemoglobin and serum thiocyanate determinations as indicators of cigarette smoking. Am J Public Health 1980; 70: 284-6.

${ }^{26}$ Farquhar JW. The community-based model of life style intervention trials. Am J Epidemiol 1978; 108: 103-11.

${ }^{17}$ Sherwin R. Controlled trials of the diet-heart hypothesis : some comments on the experimental unit. Am J Epidemiol 1978; 108: 92-9.

1s Cornfield J. Randomization by group : a formal analysis. Am J Epidemiol 1978; 108: 100-2.

10 Sutherland I. Estimates of pressor effect and regression towards the mean in the intervention study. Hart Bull 1977; 8: 68-71. 